\title{
VI. Observations on the notations employed in the differential and integral calculus
}

J.J.

To cite this article: J.J. (1844) VI. Observations on the notations employed in the differential and integral calculus, Philosophical Magazine Series 3, 24:156, 25-37, DOI: $10.1080 / 14786444408644795$

To link to this article: http://dx.doi.org/10.1080/14786444408644795

曲 Published online: 30 Apr 2009.

Submit your article to this journal $\lceil\pi$

Џ Article views: 3

Q View related articles $\asymp$ 


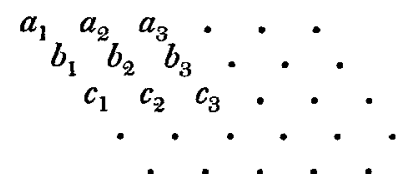

Let $X_{m}$ and $X_{m+1}$ be any two consecutive limiting polynomials; then, since $\mathrm{X}_{m}$ and $\mathrm{X}_{m+1}$ have like and contrary signs immediately before and after the passage of a root of the equation $\mathrm{X}_{m}=0$ (Young on Equations, art. 76), it is manifest, by inspecting the above arrangement of the roots, that one variation, and only one, will be introduced on the passage of each root of the equation $\mathrm{X}=0$; the value of $x$ being supposed to continually decrease from the greatest root downwards. Now, since all the positive roots are comprised between 0 and $\infty$, it follow's, from what is proved above, that the number of variations arising from making $x=0$ will exhibit the number of positive roots in the equation; which variations, it is manifest, are the same, both in number and order, as those of the original equation.

It is proved in exactly the same manner as above, the value of $x$ being supposed to increase from the least root upwards, that no equation can have a greater number of negative roots than permanencies, or successive repetitions of the same sign.

Cor.-It is also plain that, if any two numbers be substituted for $x$ in the functions $\mathrm{X}, \mathrm{X}_{1}, \mathrm{X}_{2}, \mathrm{X}_{3}, \& c$., the difference between the number of variations, in the signs of the results of these substitutions, will express exactly the number of roots comprised between these two numbers.

Preston, November 5, 1843.

Yours, \&c.,

Septimus Tebay.

VI. Observations on the Notations employed in the Differential and Integral Calculus. By J. J.*

THE differential and integral calculus are applied to nearly the whole circle of the physical sciences; scarcely any treatise on mechanics, optics, astronomy, \&c. can be read so as to be understood without a thorough knowledge of these extensively useful adjuncts, or at all events without a pretty close acquaintance with them. It is clearly expedient then that sciences so generally applied and so constantly occurring should be kept as simple as possible. The symbols employed should be as free as they can be from ambiguity, at the same

\footnotetext{
* Communicated by the Author.
} 
time, there should be nothing cabalistic or mystifying about them. The sciences are nearly universal in their application, so likewise should be their notation; and to this end, there should be a sort of unity about it which would at once identify it; so that when a reader opens a scientific treatise he may know at a glance what calculus is adopted in its demonstrations. He can then begin to read it, but obviously this cannot be done, if he have been accustomed to one kind of nota. tion and a totally different one be used in the book: he must in the first place learn his letters, and if no explanation be given, it may require much time and trouble to bring him acquainted with an old friend disguised in a new dress: he may have learned Greek and be competent to read that language; but he may not be able to read the same thing in Hebrew characters. Clearly, if one kind of symbolical language expresses either of the sciences named more accurately or more logically than another, that language ought to be generally adopted, and no other used : such language ought to make its appearance in every treatise having any pretensions to elegance, and all others be made over for the exclusive employment of scientific charlatans.

Could writers on the differential and integral calculus agree upon the point, as to which is the most accurate mode of expressing the various processes to which they are applied, and use no other, and would the authors of other scientific works adopt only the language thus set apart, they would very much indeed simplify those important sciences, as well as their applications: they would save their young readers a great deal of useless trouble: they would also, by giving a oneness and a generality to the symbols employed, remove from those sciences that shifting, or as some term it hocus pocus sort of character, to which their appearing now in one form and then in another certainly entitles them.

Moreover, if one has learned to read a mathematical process in one symbolical language, it would be difficult to prove how it adds a particle to his knowledge to be able to read it in another; and therefore the timeand the trouble that it costs him in learning to read the process in its new dress is time lost and labour thrown away. It is supposed that this position will not be disputed by the advocates of either notation, and if this be the case, it surely behoves men of competent authority to consider the subject with the view of rescuing it from such a stigma; it is hoped that they will endeavour to prevent the votaries of science from having their time thus uselessly wasted; from being needlessly puzzled by different notations or bewildered by a mixture: to realize this hope, by calling 
due attention to the matter, is the object of the preceding and subsequent remarks.

Up to a recent period the fluxional notation was commonly used by English mathematicians. Mr. Woodhouse assigned reasons for the adoption of the differential instead of the fluxional notation in the preface to his Principles of Analytical Calculation, published in 1803 ; he employed the differential method in an elaborate paper published in the Philosophical Transactions in the next year: previously he had used the fluxional notation. The English trans!ation of Lacroix was published in 1816; the differential notation first occurred in the Cambridge Problems in 1817. I believe its first appearance in any English mathematical periodical was in the second volume of the Mathematical Repository, in a solution by $\mathrm{Mr}$. Ivory.

In the translation of Lacroix's Differential and Integral Calculus just named, it was laid down that if $u$ be a function of $x$ and $u=a x^{3}$, then $d u=3 a^{2} d x$, and $\frac{d u}{d x}=3 a x^{2}$; the first expression was termed the "differential" of the equation, the latter was called its " differential coefficient."

I believe this notation has generally been since used by writers on the differential calculus, both in England and elsewhere ; another mode of differentiating, however, has been partially adopted at Cambridge, or perhaps it may be more accurately termed a substitute for differentiating; it has been called "the calculus of differential coefficients:" instead of writing $\frac{d u}{d x}$, for the differential coefficient as above, they write $d_{x} u:$ if $u$ and $z$ be functions of $x$, they write

$$
d_{x}(u z)=u d_{x} z+z d_{x} u \text {. }
$$

Similarly, $d_{x}\left(u^{z}\right)=u^{z}\left(z \frac{d_{x} u}{u}+\log _{\varepsilon} u d_{x} z\right)$.

The radius of curvature is thus expressed :-

$$
r=-\frac{1}{d_{x^{2}}^{2} y}\left\{1+\left(d_{x} y\right)^{2}\right\}^{\frac{3}{2}} \text {. }
$$

The equations of motion are thus written :-

$$
\begin{aligned}
d_{t} x & =\text { velocity parallel to } x \\
d_{t} y & =\text { velocity parallel to } y \\
d_{t} z & =\text { velocily parallel to } z \\
d_{t}^{2} x & =\mathrm{X} d_{t}^{2} y=\mathrm{Y} d_{t}^{2} z=\mathrm{Z}
\end{aligned}
$$

It is well known that these expressions are usually written,

$$
\frac{d x}{d t}, \frac{d^{2} x}{d t^{2}}, 8 \mathrm{c} .
$$

Perhaps Mr. Jarrett's paper on algebraic notation in the third 
volume of the Cambridge Transactions, printed in 1827, contained the first specimen of the index subscript-notation, though he says Prony and others had previously employed it; the subscript notation, or the calculus of differential coefficients, has found its way into some treatises on mathematical subjects. It is supposed the above examples will be sufficient to indicate the difference between the subscript notation and that more generally used; but in order to become a proper judge of the difficulty in reading a book written in the new notation, after one has been accustomed to the common one, the reader must go through the task himself; and his qualification to give an opinion will be all the better, if he have to commence with finding out what the new notation really means.

The notation of Lacroix (that is the notation employed by him) has been so generally used in mathematical works during many years, that some strong reason ought to be given for introducing another; on this head, however, I have met with only one advocate, namely, the author of a small work entitled " On the Notation of the Differential Calculus." The work is said to be scarce; my copy has no title-page, but the book was printed by Metcalf, Cambridge, some time ago. The author is understood to be a very distinguished member of the University; the reader should refer to the book for practical illustrations and for the full scope of the writer's object; only some extracts, strictly bearing upon the point under consideration, can be taken on the present occasion.

Art. 32. The author says, "We must observe that since $d u$ is obtained from $u$ by performing upon it some operation with regard to $x$, of which it is a function, it is necessary when $u$ is a function of several independent variables $x, y, z$, ... to know with regard to which of them the operation $d$ is to be performed, for the results may be very different according as $d$ is performed with regard to the one or the other. And herein the notation of differentials is defective, for when we meet with the expression $d u$ it is impossible to know what it represents. We know, indeed, that an operation of a certain kind is to be performed on $u$ in respect to some quantity of which $u$ is a function, but which is that quantity it is impossible to tell. Hence arises all that confusion and obscurity from which very few, if any, treatises on differentials are free; and in this respect also it is very much inferior to the calculus of differential coefficients, which is remarkable for its perspicuity."

Art. 42. "Whenever $u$ is a function of one independent variable, the differential coefficients may be represented by the fractions $\frac{d u}{d x}, \frac{d^{2} u}{d x^{2}}, \frac{d^{3} u}{d x^{3}} \ldots \ldots \ldots \ldots$ 
"But if $u$ be a function of two independent variables $x$ and $y$, then, because $d u=d_{x} u d x+d_{y} u d y$,

we have

$$
d_{x} u=\frac{d u}{d x}-d_{y} u \frac{d y}{d x},
$$

from which it appears that the differential coefficient $d_{x} u$ can no longer be represented by the fraction $\frac{d u}{d x}$. Hence the only notation which is inconsistent with itself, and consequently erroneous in principle, is precisely that which is most used in this University, viz. the representing differential coefficients by fractions $\frac{d u}{d x}, \frac{d^{2} u}{d x^{2}}$

"This ought to be a sufficient reason for rejecting it and endeavouring to invent another which shall at least be con-

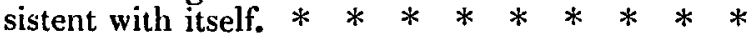

"The ridiculous subterfuges to which writers have been driven by the use of $\frac{d u}{d x}, \frac{d^{2} u}{d x^{2}} \ldots$ render it a matter of wonder that that notation has not long ago been banished from every mathematical treatise."

The writer concludes his work by giving the following examples of the confusion arising from the common, which he terms inconsistent notation.

" At page 175 of the Cambridge translation of Lacroix's Differential and Integral Calculus, we have these two equations :

$$
\frac{d u}{d x}+\frac{d u}{d z} \cdot \frac{d z}{d x}=0, \text { and } \frac{d u}{d y}+\frac{d u}{d z} \cdot \frac{d z}{d y}=0,
$$

on which the author remarks, 'the $d z_{j}$ of the first equation must not be confounded with the $d z$ of the second.' Now we ask, what is there to distinguish $d z$ in the one from $d z$ in the other? Nothing. In fact, this remark alone ought to have been sufficient to demonstrate the necessity of an improvement in the notation. A little below in the same page, we find the two following explanatory equations:

$$
d z=\frac{d z}{d x} \cdot d x, \text { and } d z=\frac{d z}{d y} \cdot d y,
$$

which we hold to be utterly unintelligible, though they are given by way of explaining the mystery of their predecessors above.

"We shall take our next example from a book, the title of which it is not necessary to mention.

" ' $z$ being a function of $x$ and $y$, two independent quantities, 
the following equation is said to express the connexion between $\frac{d z}{d x}$ and $\frac{d z}{d y}$,

$$
\frac{d z}{d x}=\frac{d z}{d x}+\frac{d z}{d y} \cdot \frac{d y}{d x} . . . . . .
$$

from which we should naturally conclude that

$$
0=\frac{d z}{d y} \cdot \frac{d y}{d x}
$$

"Now we ask, what connexion does this establish between $\frac{d z}{d x}$ and $\frac{d z}{d y}$ ? Certainly none. In order, however, to explain how equation (1.) does represent such a connexion, we are told that $\frac{d z}{d x}$ on the left-hand side of the equation does not mean the same as $\frac{d z}{d x}$ on the right-hand side;' an explanation not likely to be very satisfactory to a learner."

The above are the strongest reasons, indeed the only reasons, that $I$ have seen advanced for adopting the new notation. I have made these extracts, in order to set the writer's most cogent arguments before the reader; still, I would advise him to peruse the book and form his own judgement.

With regard to the above quotations, I wish briefly to remark, that it seems to me the reference to Lacroix is not sufficiently explicit to do justice to that work. It should be observed that the two differential equations taken from that work belong to two sections of the curve surface, the equation of which is $u=0$; and " the $d z$ of the first equation must not be confounded with that of the second, for they are both only partial differentials, as has been remarked in No.120."

I do not pretend to determine the point, but I am impressed with the notion that a careful perusal of Arts. 120 and 127 in Lacroix, upon which the equations cited depend, will clear up the mystic appearance which they bear in the pamphlet. With respect to the equations $d z=\frac{d z}{d x} \cdot d x$ and $d z=\frac{d z}{d y} \cdot d y$, said to be given in Lacroix by way of explaining the mystery, this is what Lacroix really does say :-

"When we have $d z=p d x, d z$ is the differential of the ordinate of the section parallel to the plane of $x$ and $z:$ and similarly, $d z=q d y$ is that of the ordinate of the section parallel to the plane of $y$ and $z ;$ " here $p=\frac{d z}{d x}$ and $q=\frac{d z}{d y}$ : I am unable to perceive that these equations were intended 
to clear up the mystery ascribed to the equations first mentioned. Similar equations to the sections parallel to the planes $z x$ and $z y$ have been given in Higman's Syllabus, and in other works : perhaps the geometric signification of the equations cited ought not to be overlooked in criticising them. Whether the author, the title of whose book is not mentioned, himself clears up the apparent paradox that " $\frac{d y}{d x}$ on the lefthand side of the equation does not mean the same as $\frac{d z}{d x}$ on the right side," does not appear. I do not know that I have his book, and therefore shall leave the author to take care of himself.

Perhaps it is impossible fully to illustrate the subject entirely free from paradox: thus the writer of the pamphlet on page 24, says, "the reader must keep in mind, that though $x$ appears in the expression $d x$, yet $d x$ is entirely independent of $x$," \&c.: if $d x$ have nothing to do with $x$, the quantity, or whatever $x$ denotes, must have been altogether annihilated, or completely changed, in becoming $d x$, and in that case $x$ in the latter expression ought to have been some other symbol, to prevent what Berkeley calls a fallacia suppositionis, or, " $a$ shifting of the hypothesis."

The writer of the pamphlet in Art. 26, and Professor Miller, (Differential Calculus, Art. 3), state the operations which $d_{x}$ denotes when affixed to a function of $x$; there is, or at least I fancy there is, a material disparity in their statements; the reader can if he please turn to the works and judge for himself; my object for naming the circumstance is, because one of the books was written apparently to recommend the new notation, and the other is the only elementary treatise that $I$ know in which it is used.

Having cited the above reasons in favour of the $d_{x}$ notation, I will now quote two opinions on the other side of the question. Mr. W. S. B. Woolhouse, in a very valuable disquisition on the fundamental principles of the Differential and Integral Calculus, published in the Appendices to the Gentleman's Diary for 1835 and 1836 , says, "Before closing this paper I cannot refrain from adding a remark on a new plan of differential notation that has lately been introduced, and to a considerable extent adopted at Cambridge. I allude to the substitution of $d_{x} y$ for $\frac{d y}{d x}, d_{x}^{2} y$ for $\frac{d^{2} y}{d x^{2}}$, and others of a similar kind, which possess no recommendation whatever except it be that of novelty: and I feel convinced that this change is suited only to such persons as are satisfied with mere hocus 
pocus operations on optical symbols without any regard to the mental images they are designed to represent. In the higher branches of analysis this new-fangled notation will defy the presence of anything like distinct ideas: for instance, an elemental parallelopiped $d_{x} d y d z$ is reduced to the confused and incomprehensible form $d_{x} y d_{x} z d x^{3}$. It is the duty of every mathematician to make known his opinion concerning it."

Mr. Woolhouse's attainments are such, that his opinion upon this, or upon any other mathematical subject, is certainly deserving of respect.

A writer in the Northumbrian Mirror, new series, p. 89, says, "We cannot conclude without noticing the clumsy differential notation which has recently captivated the publishers of mathematical works at Cambridge; it offends against simplicity, symmetry and clearness; it is a meretricious show of conciseness, and an innovation that every lover of simplicity, brevity and neatness, should repudiate.

"In the differential coefficients of two or more varieties the expression is, of necessity, so overloaded with those little ugly off-shoots growing out of the side and stem that the body of the tree is almost hidden from the view."

I have made this quotation to show the writer's opinion, I certainly do not see that a little $x$ deserves to be called ugly any more than a great one, but the phraseology is the writer's; however, it will be observed that the opinions on each side are made pretty strong.

The integral calculus is the reverse of the differential; integration is commonly denoted by the symbol $f$ : thus, $d \cdot \sqrt{a^{2}+x^{2}}=\frac{x d \dot{x}}{\sqrt{a^{2}+x^{2}}}$ and $\int \frac{x d x}{\sqrt{a^{2}+x^{2}}}=\sqrt{a^{2}+x^{2}}$.

In the suffix notation for integrals the sign of integration is $f_{x}$; in this case only the differential coefficients are employed: if the $d_{x}$ notation be employed at the same time, then $\int_{x}$ is the symbol of an operation precisely the reverse of $d_{x}$; thus-

and

$$
d_{x} \cdot \sqrt{a^{2}+x^{2}}=\frac{x}{\sqrt{a^{2}+x^{2}}}
$$

$\int x \sqrt{\sqrt{a^{2}+x^{2}}}=\sqrt{a^{2}+x^{2}}$.

The suffix notation for integrals is found in many of the mathematical works at Cambridge; for instance, Hymer's Integral Calculus and Differential Equations, Murphy on Electricity, Earnshaw's Works, Airy's Tracts, \&c.

'Ihe authors just mentioned are an honour to one of the first universities in the world; they are stars of the first mag- 
nitude in that firmament of science. Every one must feel that a notation employed by such anthors must have some peculiar advantages to recommend it; still I believe neither of these celebrated writers has given any reason for adopting the suffix notation in preference to the common one. I wish they had, but as the matter stands I can only adduce their names in support of the $f_{x}$ mode. On the other hand I wish to cite the reasons of two justly esteemed authors for employing the old notation.

Mr. Pratt, in the preface to his ' Principles of Mathematical Philosophy,' ed. 1835, says, "The prevailing argument with me for using the old differential and integral notation is the excellence of Fourier's notation for definite integrals. I much prefer that to any other that I have seen, and this naturally led me back to the old form of differentials and integrals. In case any of my readers are not acquainted with Fourier's notation, I now give it: $\int_{a}^{b} u d x$ represents the integral of the differential coefficient $u$, or of the differential $u d x$, with respect to $x$ taken between the limiting values $a$ and $b$ of $x$. In successive integrations the order of arrangement of the integrals is the same as that of the differentials: thus $\int_{-1}^{1} \int_{0}^{2 \pi} \mathrm{P} d \mu d \omega$ represents the double integral of $\mathbf{P}$ with respect to $\mu$ and $\omega$, the limits of $\mu$ being -1 and 1 , and the limits of $\omega$ being 0 and $2 \pi . "$

Mr. Gregory, in the preface to his 'Examples of the Differential and Integral Calculus,' thus expresses himself :"I have adhered throughout to the notation of Leibnitz in preference to that which has been of late revived and partially adopted in this University. Of the differential notation I need say nothing here, as it appears to be abandoned as an exclusive system by those who introduced it; but as the suffix notation for integrals has been sanctioned by those whose names are of high authority, I may state briefly some of my reasons for differing from them.

"In the first place, on considering the subject, I could find no arguments against the use of the notation for differentials, which did not apply with even greater force against that for integrals; indeed, although there may be some cases in which the use of the former is advantageous, I know of none in which the latter does not appear to me to be inconvenient.

"In the next place, I fully agree with Professor De Morgan in an unwillingness to lose sight of the analogy to summation which is implied in the old notation: and if it were at any Phil. Mag. S. 3. Vol. 24. No. 156. Jan. 1844. 
time necessary to consider integration merely as the inverse of differentiation, I should prefer such a symbol as $d_{x}{ }^{-1}$, which expresses the required idea better than $f_{x}$. But what I look on as a fatal objection to the suffix integral notation is, that, like the corresponding one for differentials, it is not applicable to all cases. Of this any one may satisfy himself by attempting to use it in transforming a multiple integral from one system of independent variables to another, a problem which is of frequent occurrence, but which I have not seen solved analytically in any work in which the suffix notation is employed; so long, therefore, as the old notation adapts itself to all cases in which it is required, while that which is proposed is not so accommodating, there appears to me no doubt which is to be preferred."

Mr. Jarrett, in the paper before referred to, recommended Fourier's notation; every one who habituates himself to its use will, I think, admit that it is admirably adapted to effect its purpose.

In the commencement of these remarks I gave it as my opinion that new symbolic language in a scientific treatise uselessly puzzles the reader and occupies his time without increasing his knowledge; it has been, and will be, my object to make converts to this notion. Some of the writers above. named adopt the suffix notation both in differentials and integrals, others only the suffix for integrals : must not even this variety be an incumbrance to a student, and for that reason ought it not to be exploded?

Airy, in the commencement of his tracts, says, "By the notation of $f_{\theta} \cos n \cdot \theta \cdot \Theta, f_{\theta} \cos n \theta \cdot \overline{\cos m \theta}+\overline{\mathrm{D}}, \& \mathrm{c}$., we mean what are usually written $f \cos n \theta . \Theta d \theta, \int \cos n \theta \cdot \cos \overline{m \theta+\mathrm{D} d \theta}$, $\& c .$, they are the quantities whose differential coefficients with respect to $\theta$ are $\cos n \theta . \Theta, \cos n \theta \cos m \theta+\mathrm{D}, \& c . "$

To a reader who is unaccustomed to the notation, and who may perhaps here meet with it for the first time, this explanation is exceedingly useful as a key, it sets him a-going.

In some other books, however, in which the $d_{x}$ and $\int_{x}$ notations are used, not one word by way of definition is said: the reader has to find out the meaning of a new symbolic language used in investigating intricate subjects as he best may: it seems to be taken for granted, that because the writer knows the meaning of the hieroglyphics, the reader must comprehend them by sheer intuition.

At college, where lectures are constantly given, such difficulties may be well explained viva voce. But the writers of mathematical works at Cambridge should bear in mind that 
they advertise their books for sale; the celebrity that so justly attaches to the University and its members induces lovers of science who are at a distance from theUniversity, and who are not acquainted with its advantages, to purchase their works; they cannot attend the lecture-room, nor is a private tutor at hand; the explanation, therefore, that a Cambridge man can obtain on the spot should form part of the work; without it, the book at first appears to be a mathematical enigma, the solution of which wastes the student's time without at all adding to his knowledge. It is considered very prudent and discreet in men who have nothing to say, to say nothing, but this is not the case with the Cambridge authors to whom I allude. They are quite capable of writing to the purpose, and might in few words clearly explain a difficulty; in my opinion their doing so would double the value of their labours, and trebly enhance their utility; besides, it is only a matter of common justice to their general readers.

It seems to have become the fashion with many writers to eschew all introductory or explanatory matter: the reader, without preamble or preface, is at once pitched into the midst of a difficult subject entirely in a new dress, and he may make progress if he can. Works thus written under the notion that reader's intuitively know everything without being told anything, may have more matter compressed into them, but their authors lock it up and keep the key. To explain myself more clearly, I will give an example: let any one who knows nothing of the suffix notation, but who can read, for instance, a treatise on dynamics in the old, take a treatise on that subject written in the suffix language, containing no explanation whatever; let him move on as fast as he can, and tell me how he likes it.

It the reader has never met with a sudden change from one notation to another, he may find a specimen in the treatise on Mechanics in the Encyclopadia Metropolitana: up to Art. 56, the differential and integral calculus are employed; subsequently the fluxional: thus within a few lines in writing on precisely the same subject, the symbols and language are completely changed. The author of the treatise referred to is deserving of great respect, but I wish he had taken the trouble to write the article all in the same language. By way of parenthesis it may be observed that the expense of these books is considerable, and judging from their authors' celebrity, their purchasers have a right to expect the articles to be of a high order, and not mere scraps indifferently cooked and sent into the world scarce half-made up; however, many of the treatises are worthy of their authors, and are a credit to the seat of learning from which they emanate. 
It has been before remarked, that a new notation is very likely to arrest the progress of an uninitiated reader. I will mention an instance: I some time ago had the good fortune to fall in with an ingenious mechanic at Penzance, who has been for several years in the habit of answering many and sometimes most of the mathematical questions proposed in the Diaries, \&c.; he told me that he had taught himself the fluxional calculus, and that by reading the Diaries and other publications of that description, he had learned to read and to use the differential mode; but having never met with any explanation of the suffix notation, he could not at all understand it, nor had he been able with all his application to read a solution written in that language so as to comprehend the steps in the demonstration; it had baffled all his efforts, and he had given up the attempt to find out its meaning.

I for one sincerely respect the votaries of science, even when education, leisure, fortune, and every concomitant tend to. place them in the most favourable position. No one values more highly than I do the labours of professors, \&c., whose very calling, the sole business of their life, is science; whose minds are very often kept on the stretch as a mere matter of bread and cheese; but if men like these are entitled to esteem for their mental endowments-and I trust they always will beis not the man deserving of it who, after his daily manual toil of a laborious description, devotes his hours to science and, notwithstanding every disheartening difficulty, works his way up to her' most secluded walks? If this be so, should not men eminent by talent as well as by position be careful to throw no impediments in the rugged paths of such sons of genius.

At all events, I think they should; but it is possible that I may have formed a hasty or a partial judgement upon the subject, for I well know many of the difficulties attending such a course, and I readily admit that I have had the case abovenamed in my mind's eye in writing the above remarks; whetherI have been skilfully keeping to the point so as to effect my purpose or not, is a question not for me to decide: I am quite sure that each and all of the authors that $I$ have mentioned would much more willingly assist such devoted disciples of science as the very remarkable one to whom I have alluded, and indeed all others, than place the least obstruction in their arduous paths.

Many of the most esteemed mathematical authors of the day are correspondents or readers of this publication: the object of this paper has been to bring to their notice the loss of time which attends their using new notations in scientific 
treatises without any explanation, and also the uselessness, as I think, of adopting different notations to effect the same purpose. Either the common, the suffix, or some other is the best adapted for general use; which ought to be constituted and considered the standard notation, I want the opinion of your readers to settle: to elicil this, I have adduced the pith of what has been written in favour of and against the suffix mode, so that a judgement may be formed with as little trouble as possible: I have endeavoured to do my part as impartially as I could. I have aimed to state the case as fairly as $I$ could in hopes to obtain an impartial judgement from competent authority. Very likely I may have evinced a little leaning, for I do not like the suffix notation, but I trust I have said nothing distasteful to its distinguished advocates: I am willing to pay homage to their splendid achievements in science, but whilst I heartily respect their attainments, I have some misgivings as to their orthodoxy respecting the subject that has been discussed.

It may save time and trouble if I beg to be considered as the voluntary, though feeble advocate of such votaries of science as the one referred to above: as far as I am personally concerned, all writers may go on their own way rejoicing; what they may do, or may not do, will not affect me in the least: on my own account I have no favours to ask. I trust, therefore, in dealing with the subject that my mode of advocacy will be entirely overlooked.

Mr. Gregory says the $d_{x}$ notation is losing ground: if it be not defunct, I trust it will soon become so: no suffix notation appears in the last Cambridge Problems : this gives some hopes. I think there will be a unanimity in the opinion that the fountain head of mathematical science should be kept clear, that its streams should enlighten as they proceed and not darken and mystify. Those who are placed at the source would in my opinion do well to ponder on the influence they have on the scientific world, to see how much it behoves them to throw a light upon all the subjects they handle, but especially to refrain from making them repulsive by clothing them with darkness.

Should the preceding desultory remarks educe opinions which may settle a point that now appears to be doubtful, or should they have the least tendency to fix the adoption of one notation, and thus to simplify the science named at the commencement, my aims will have been fully accomplished. 